\title{
Uncertainties associated with digital elevation models for hydrologic applications: a review
}

\author{
S. P. Wechsler \\ California State University Long Beach, 1250 Bellflower Boulevard, Long Beach CA 90840, USA
}

Received: 24 April 2006 - Published in Hydrol. Earth Syst. Sci. Discuss.: 28 August 2006

Revised: 23 May 2007 - Accepted: 5 June 2007 - Published: 3 August 2007

\begin{abstract}
Digital elevation models (DEMs) represent the topography that drives surface flow and are arguably one of the more important data sources for deriving variables used by numerous hydrologic models. A considerable amount of research has been conducted to address uncertainty associated with error in digital elevation models (DEMs) and the propagation of error to derived terrain parameters. This review brings together a discussion of research in fundamental topical areas related to DEM uncertainty that affect the use of DEMs for hydrologic applications. These areas include: (a) DEM error; (b) topographic parameters frequently derived from DEMs and the associated algorithms used to derive these parameters; (c) the influence of DEM scale as imposed by grid cell resolution; (d) DEM interpolation; and (e) terrain surface modification used to generate hydrologicallyviable DEM surfaces. Each of these topical areas contributes to DEM uncertainty and may potentially influence results of distributed parameter hydrologic models that rely on DEMs for the derivation of input parameters. The current state of research on methods developed to quantify DEM uncertainty is reviewed. Based on this review, implications of DEM uncertainty and suggestions for the GIS research and user communities are offered.
\end{abstract}

\section{Introduction}

The purpose of this review is to examine the nature, relevance and management of digital elevation model (DEM) uncertainty in relation to hydrological applications. DEMs provide a model of the continuous representation of the earth's elevation surface. This form of spatial data provides a model of reality that contains deviations from the truth, or errors. The nature and extent of these errors are often unknown and not

Correspondence to: S. P. Wechsler

(wechsler@csulb.edu) readily available to users of spatial data. Our lack of knowledge about these errors constitutes uncertainty. Nevertheless, DEMs are one of the most important spatial data sources for digital hydrologic analyses as they describe the topography that drives surface flow. Use of DEMs in hydrologic studies is ubiquitous, however uncertainty in the DEM representation of terrain through elevation and derived topographic parameters is rarely accounted for by DEM users (Wechsler, 2003). DEM uncertainty is therefore of great importance to the hydrologic community.

This paper reports on representative literature on DEM uncertainty as applied to hydrologic analyses ${ }^{1}$. To understand how to address and manage DEM uncertainty, specifically in relation to hydrologic applications, it is necessary to recognize the components and characteristics of DEMs that contribute to that uncertainty. This paper provides a review of research in each of these fundamental areas which includes: (a) DEM error; (b) topographic parameters frequently derived from DEMs and the associated algorithms used to derive these parameters; (c) the influence of DEM scale as imposed by grid cell resolution; (d) DEM interpolation; and (e) terrain surface modification used to generate hydrologicallyviable DEM surfaces. Each of these topical areas contributes to DEM uncertainty and potentially influences results of distributed parameter hydrologic models that rely on DEMs for the derivation of input parameters. The current state of research on methods developed to quantify DEM uncertainty is reviewed. Based on this review, implications of DEM uncertainty and suggestions for the research and GIS user communities are suggested.

In the past decade DEM data has become increasingly available to spatial data users due to the decrease in data and computer costs and the increase in computing power.

\footnotetext{
${ }^{1}$ Given the burgeoning nature of this literature, it regrettably has not been possible to cite every publication on this topic. An attempt has been made to give examples of studies related to focal variables.
} 
DEMs produced from technologies such as Light Detection and Ranging (LiDAR) and Interferometric Synthetic Aperture Radar (IFSAR) sensors are more readily available. These remotely-sensed DEM production methods provide users with high resolution DEM data that have stated vertical and horizontal accuracies in centimeters, making them more desirable, yet costly in both dollars and processing requirements. DEM users with limited budgets can obtain DEMs from government sources or can conduct field surveys using global positioning systems (GPS) and interpolate DEMs for smaller study areas. No matter the source, DEM products provide clear and detailed renditions of topography and terrain surfaces. These depictions can lure users into a false sense of security regarding the accuracy and precision of the data. Potential errors, and their effect on derived data and applications based on that data, are often far from users' consideration (Wechsler, 2003).

In colloquial terms, the word error has a negative connotation, indicating a mistake that could have been avoided if enough caution had been taken (Taylor, 1997). However, errors are a fact of spatial data and often cannot be avoided. In the context of spatial data, errors are often unavoidable and therefore must be understood and accounted for. There has been much discussion in the literature regarding philosophies (Fisher, 2000), ontologies (Worboys, 2001) and definitions (Heuvelink, 1998; Refsgaard et al., 2004) of spatial data uncertainty. For the purposes of this discussion of DEM uncertainty, the term error refers to the departure of a measurement from its true value. Uncertainty is a measure of what we do not know about this error and its impact on subsequent processing of the data. In the spatial realm, errors and resulting uncertainty can never be eliminated.

Our responsibilities as DEM data users and researchers are to accept, search for and recognize error, strive to understand its nature, minimize errors to the best of our technical capabilities, and obtain a reliable estimate of their nature and extent. Based on these understandings, the tasks are to develop and implement methods to quantify and communicate the uncertainty associated with the propagation of errors in spatial data analyses. The research reported in this paper brings together knowledge about the components and characteristics of DEM uncertainty specifically related to hydrologic applications

\section{DEM error and accuracy}

\subsection{DEM error}

DEM errors (the departure of a given elevation from truth) have been well documented in the literature (Pike, 2002). DEM errors are generally categorized as either systematic, blunders or random (USGS, 1997). Systematic errors result from the procedures used in the DEM generation process and follow fixed patterns that can cause bias or artifacts in the fi- nal DEM product. When the cause is known, systematic bias can be eliminated or reduced. Blunders are vertical errors associated with the data collection process and are generally identified and removed prior to release of the data. Random errors remain in the data after known blunders and systematic errors are removed.

Sources of DEM errors have been described in detail, see for example (Burrough, 1986; Heuvelink, 1998; Pike, 2002; Wise, 1998). Error sources have been summarized as (a) data errors due to the age of data, incomplete density of observations or spatial sampling; (b) processing errors such as numerical errors in the computer, interpolation errors or classification and generalization problems; and (c) measurement errors such as positional inaccuracy (in the $\mathrm{x}$ and $\mathrm{y}$ directions), data entry faults, or observer bias.

\subsection{DEM production methods and sources of error}

Sources of DEM errors are inextricably linked to DEM production methods. These include field surveying (using tacheometers or global positioning systems), photogrammetry, surface sensing technologies such as Light Detection and Ranging (LiDAR), Interferometric Synthetic Aperture Radar (IFSAR) or sonar (for bathymetric data), and digitizing from existing maps.

Errors are specific to the various production techniques. For example, the error budget for a LiDAR DEM is related to the contributing errors in data acquisition subsystems such as the laser rangefinder, global positioning system and inertial measurement unit (IMU) (Airborne1, 2006).

Once elevation data is collected, DEMs are generated using interpolation or aggregation techniques. A detailed review of various interpolation approaches can be found in (Burrough and McDonnell, 1998; Burrough, 1986; Wood, 1996). Often little is known about the error either occurring during or generated as a result of the interpolation (Desmet, 1997) or aggregation process. Uncertainty associated with interpolation procedures has been a focus of practitioners and researchers in the geostatistical community (Dubois et al., 1998). However, relatively few studies explicitly address the impact that different interpolation methods have on a resulting DEM. A detailed review of various interpolation approaches can be found in (Burrough and McDonnell, 1998; Burrough, 1986; Wood, 1996). The following are examples of efforts to examine error that result from interpolation. Wood and Fisher (1993) and Wood (1996) applied visualization techniques to identify DEM interpolation errors. Desmet (1997) investigated the effect of interpolation on precision (accuracy of the predicted heights) and shape reliability (degree of fidelity in the spatial pattern of topography) expressed by derived topographic parameters. Wise (1998) investigated the effect of interpolating DEMs from contours using different algorithms. Differences in results were attributed to the complex interactions between algorithms for both interpolation and derivation of DEM-derived topographic parameters 
(Wise, 1998). Erxleben et al. (2002) evaluated the accuracy of snow water equivalents derived from DEMs generated using four interpolation methods. Kienzle (2004) tested the quality of DEMs interpolated at different resolutions and identified an optimum grid cell size that was determined to be between 5-20 $\mathrm{m}$ depending on terrain complexity. These studies reveal the variety of applications that are affected by DEM error and the efforts of researchers to document and to accommodate for error.

\subsection{Quantifying DEM error}

In the United States, national map accuracy standards provide statistical guidelines for estimating the positional accuracy of digital geospatial data (FGDC, 1998). DEM vendors establish threshold accuracies for specific products based on technological capabilities. DEM accuracy is quantified using the Root Mean Square Error (RMSE) statistic. To compute the RMSE, differences between the source dataset and co-located values from an independent source of higher accuracy are computed. The RMSE is the square root of the average of these squared differences.

The RMSE assumes that DEM errors are random (FGDC, 1998). Because the RMSE is used as a measure of spread, it requires the assumption of normality (Monckton, 1994), which is often violated in the case of the DEM. While a valuable quality control statistic, the RMSE does not provide an accurate assessment of how well each cell in a DEM represents a true elevation.

The following example demonstrates the limitations of the RMSE. A LiDAR dataset that consists of roughly 120 million points has a stated vertical accuracy (RMSE) of $0.15 \mathrm{~m}$. This value was computed from an external ground survey of 174 co-located points (representing $0.00014 \%$ of the dataset). A normal distribution with a mean of 0 and a standard deviation of 0.15 could range from -0.62 to +0.62 . The vendor assures $95 \%$ of the data could deviate from the stated elevation by $0.15 \mathrm{~m}$ or less. However, five percent of the values (six million points) could deviate by \pm 0.15 to $\pm 0.30 \mathrm{~m}$ and $1 \%$ ( 1.2 million points) by \pm 0.30 to $\pm 0.62 \mathrm{~m}$. The RMSE's adequacy in representation of the dataset's accuracy is questionable.

Maune (2001) provides a detailed review of DEM production methods and associated quality assessment. This includes source, size and spatial structure of error associated with different DEM production techniques. Examples of studies that have evaluated the accuracy of various DEM products are: DEMs produced from synthetic aperture radar (SAR) (Wang and Trinder, 1999), the Shuttle Radar Topography Mission (SRTM) (Miliaresis and Paraschou, 2005; Suna et al., 2003), USGS DEMs (Berry et al., 2000; Shan et al., 2003), and comparisons of various DEM production methods (Li, 1994). While methods to assess and reduce DEM error have been developed (Hengl et al., 2004; Li, 1991; Lopez, 2002), errors persist. The inability to specify the relative con- tribution of these errors and quantify their nature and extent in a DEM product results in uncertainty.

Assessment of DEM uncertainty requires more information on the spatial structure of DEM error - beyond that provided by the RMSE. DEM vendors have been urged to provide additional DEM quality information such as "maps of local probabilities for over or underestimation of the unknown reference elevation values from those reported in the DEM, and joint probability values attached to different spatial features" (Kyriakidis et al., 1999, p. 677). DEM data products should not only include information on standard errors associated with data values, but also provide values for error contributed by other sources, such as components of the production methods, so that DEM error can be correctly assessed (Heuvelink et al., 2007).

To date, information beyond the RMSE is not readily provided to DEM users. Most DEM users will not take the time or spend the money to obtain such data sets in order to conduct DEM error assessment (Wechsler, 2003). Because information on sources of error are not readily available, it is currently often difficult, if not impossible, to recreate the spatial structure of error for a particular DEM. As demonstrated in the example above, quality control data points represent only a small percentage of a dataset and are insufficient to quantify the spatial structure of the DEM's error. Knowledge about the spatial structure of error is an important component for gaining an understanding of where errors arise and uncertainty is propagated. DEM vendors should be urged to provide information that can be used to derive this and DEM users must be able to easily apply such information for it to be of use. Therefore the research and software communities should develop DEM assessment methods that accommodate detailed DEM error information when available, and provide mechanisms for addressing uncertainty in the absence of this information.

\section{Computation of topographic parameters for hydro- logic analyses}

Topographic attributes frequently used in hydrologic analyses are derived directly from DEMs. DEM errors propagate to derived parameters. While numerous algorithms exist to generate these hydrologic parameters, GIS software packages limit users' ability to select specific algorithms. Additionally, the hydrologic community has not reached a consensus on appropriate algorithms for certain topographic parameters (such as flow direction). This section discusses the calculation of certain topographic parameters from DEMs and identifies considerations related to their contribution to uncertainty in hydrologic applications.

The raster grid structure lends itself well to neighborhood calculations that are frequently used to derive hydrologic parameters directly from a DEM. Primary surface derivatives such as slope, aspect and curvature provide the basis for 
characterization of landform (Evans, 1998; Wilson and Gallant, 2000). The routing of water over a surface is closely tied to surface form. Flow direction is derived from slope and aspect. From flow direction, the upslope area that contributes flow to a cell can be calculated, and from these maps, drainage networks, ridges and watershed boundaries can be identified. Topographic, stream power radiation and temperature indices are all secondary attributes computed from DEM data. Wilson and Gallant (2000) provide a detailed review of the DEM-derived primary and secondary topographic attributes. Research has demonstrated that DEMderived topographic parameters are sensitive to both the quality of the DEMs from which they are generated (Bolstad and Stowe, 1994; Wise, 2000) and the algorithms that are used to produce them.

Numerous algorithms exist for calculating topographic parameters. For example, slope is calculated for the center cell of a $3 \times 3$ matrix from values in the surrounding eight cells. Algorithms differ in the way the surrounding values are selected to compute change in elevation (Carter, 1990; Dunn and Hickey, 1998; Guth, 1995; Hickey, 2001; Skidmore, 1989). Different algorithms produce different results for the same derived parameter and their suitability in representing slope in varied terrain types may differ. The slope algorithm developed by Horn (1981) and currently implemented in ESRI GIS products is thought to be better suited for rough surfaces (Burrough and McDonnell, 1998; Horn, 1981). The slope algorithm presented by Zevenbergen and Thorne (1987), currently implemented in the IDRISI GIS package (Eastman, 1992), is thought to perform better in representing slope on smoother surfaces (Burrough and McDonnell, 1998; Zevenbergen and Thorne, 1987).

The routing of flow over a surface is an integral component for the derivation of subsequent topographic parameters such as watershed boundaries, and channel networks. Many different algorithms have been developed to compute flow direction from gridded DEM data and are referred to as single or multiple flow path algorithms. The single flow path method computes flow direction based on the direction of steepest descent in one of the 8 directions from a center cell of a $3 \times 3$ window (Jenson and Domingue, 1988), a method referred to as D8. The D8 algorithm is the flow direction algorithm that is provided within mainstream GIS software packages (such as ESRI GIS). However, the users in the hydrologic community recognize that the D8 approach oversimplifies the flow process and is insufficient in its characterization of flow from grid cells. In response, researchers have developed multiple flow path methods that distribute flow in all possible down-slope directions, rather than just one; see for example (Costa-Cabral and Burgess, 1994; Quinn et al., 1991; Tarboton, 1997; Wolock and McCabe, 1995; Zhou and Liu, 2002). Multiple flow path methods attempt to approximate flow on the sub-grid scale. Multiple flow path functions are currently not part of standard GIS packages and are therefore not readily available to DEM users. Desmet and Govers
(1996) compared six flow routing algorithms and determined that single and multiple flow path algorithms produce significantly different results. Thus any analysis of contributing areas such as watersheds or stream networks can be greatly affected by the algorithm implemented. Other approaches to deriving channel networks and watershed boundaries have been developed such as those that incorporate additional environmental characteristics (Vogt et al., 2003).

Unfortunately, GIS packages do not differentiate between rough and smooth surfaces when applying a slope or provide users with any options when it comes to derivation of terrain parameters. Users cannot choose a particular method; only one algorithm for derivation of parameters such as slope, aspect and flow direction is embedded in a particular GIS software package. This lack of flexibility in software capability introduces the likelihood of further error transferred to derived topographic parameters. Additional research on the appropriateness of certain algorithms for various terrain types is needed. Future GIS software packages should accommodate research needs by providing flexibility in the algorithms available to users. The ability to represent topographic complexity is controlled by the DEM's grid cell resolution. Systematic errors are introduced into topographic parameters, specifically slope, computed in flat areas and (Wechsler, 2000) and slopes computed for the same DEM but using a higher grid cell resolution results in larger computed slope values.

\section{DEM resolution and scale for representing topography}

Theobald (1989) noted that “... seldom are errors described in terms of their spatial domain, or how the resolution of the model interacts with the relief variability." (p. 99). This continues to be a concern for users.

The raster GIS grid cell data structure makes it possible to represent locations as highly defined discrete areas. The size of a grid cell is commonly referred to as the grid cell's resolution, with a smaller grid cell indicating a higher resolution. DEM accuracy has been shown to decrease with coarser resolutions which average elevation within the support $(\mathrm{Li}$, 1992). Smaller grid cell sizes allow better representation of complex topography. These high resolution DEMs are better able to refine characteristics of complex topography that are missed in coarser DEMs. This has led many DEM users to seek the highest DEM resolutions possible, increasing the costs associated with both data acquisition and processing. However, is higher resolution necessarily better? To what extent is the grid cell resolution a factor in the propagation of errors from DEMs to derived terrain parameters? Studies have addressed these questions.

DEM-derived data is generated to emulate or predict a process. The scales of environmental processes are often unknown because they occur at a range of scales. Topography 
is a result of many different processes operating over a range of spatial and temporal scales. DEM resolution imposes process and measurement scales on topography and thus hydrologic analyses. Scale questions must be addressed to fully understand earth processes, and how these processes are reflected in the geographic pattern and form of the landscape (Quattrochi and Goodchild, 1997).

DEM resolution has been shown to impact a wide range of hydrologic derivatives. These include: flow direction (Usul and Pasaogullari, 2004), topographic index (Quinn et al., 1991; Quinn et al., 1995; Rodhe and Seibert, 1999; Valeo and Moin, 2000), drainage properties such as channel networks and flow extracted from DEMs (Garbrecht and Martz, 1994; Lacroix et al., 2002; Tang et al., 2001; Wang and Yin, 1998). Other hydrologic applications have been impacted including the spatial prediction of soil attributes (Thompson et al., 2001), computation of geomorphic measures such as area-slope relationships, cumulative area distribution and Strahler stream orders (Hancock, 2005), modeling processing of erosion and sedimentation (Schoorl et al., 2000), computation of soil water content (Kuo et al., 1999), slope and specific catchment area as applied to landslide modeling (Claessens et al., 2005) and output from the popular rainfall-runoff model TOPMODEL (Brasington and Richards, 1998; Saulnier et al., 1997). DEM resolution has also been shown to directly impact hydrologic model predictions from TOPMODEL (Band and Moore, 1995; Quinn et al., 1995; Wolock and Price, 1994; Zhang and Montgomery, 1994), the SWAT model (Chaplot, 2005; Chaubey et al., 2005), and the Agricultural Nonpoint Source Pollution (AGNPS) (Perlitsh, 1994; Vieux and Needham, 1993). The Water Erosion Prediction Project (WEPP) model, however, was not sensitive to coarser resolution DEMs unless the resolution compromised watershed delineation (Chochrane and Flanagan, 2005).

The impact of grid cell resolution on terrain parameters has been shown to be related to both topographic complexity and the nature of the algorithms used to compute terrain attributes. For example, a variety of algorithms have been used to compute slope from grid-DEMs using various grid cell resolutions. In each case, as the DEM resolution became finer the calculated maximum slope became larger (Armstrong and Martz, 2003; Bolstad and Stowe, 1994; Carter, 1990; Chang and Tsai, 1991; Gao, 1997; Jenson, 1991; Toutin, 2002; Yin and Wang, 1999). Larger slope values in higher resolution DEMs can specifically be attributed to the nature of the slope algorithm, in which the grid cell resolution is effectively the "run" in the rise-over-run formula.

Research to determine an appropriate grid cell resolution for particular analyses has been undertaken (Albani et al., 2004; Kienzle, 2004). The literature has established that the grid cell size of a raster DEM significantly affects derived terrain attributes (Kienzle, 2004). Research has also demonstrated that higher resolution is not necessarily better when it comes to the computation of DEM derived topographic parameters (Wechsler, 2000; Zhou and Liu, 2004) and contributes to the propagation of errors to derived parameters under uncertain conditions (Wechsler, 2000). Selection of an appropriate resolution ultimately depends on characteristics of the study area such as topographic complexity, nature of the analysis, and finances available to purchase high resolution DEM data if appropriate.

The repeated outcomes of the effects of grid cell resolution in various hydrologic applications suggest that grid cell resolution will remain an important factor in our understanding, assessment and quantification of the propagation of DEM errors to hydrologic parameters and resulting uncertainty in related modeling applications.

Variability at scales larger than those captured by the grid cell area, referred to as sub-grid variability, exists, but has for the most part, been ignored. To date, sub-grid information is either unavailable or lost through interpolation techniques. However, as technologies progress and more and more data becomes available from DEM production methods (such as LiDAR which produces millions of data points used for DEM interpolation), sub-grid information could be retained. Methods to differentiate data from noise will need to be developed. This additional information could become a useful component for future DEM uncertainty estimations. Modifications to the raster grid cell structure should allow larger grid cells for representation of flatter areas and smaller grid cells for areas of topographic complexity, all within the same DEM. This coupled with appropriate algorithms for varied topography may lead to more appropriate representation of terrain surfaces for hydrologic applications.

\section{Surface modification for hydrologic analyses}

Overland flow routing through grid cells of a DEM requires a DEM without disruptions. DEMs often contain depressions that result in areas described as having no drainage, referred to as sinks or pits. These depressions disrupt the drainage surface, which preclude routing of flow over the surface. Sinks arise when neighboring cells of higher elevation surround a cell, or when two cells flow into each other resulting in a flow loop, or the inability for flow to exit a cell and be routed through the grid (Burrough and McDonnell, 1998; ESRI, 1998). Hydrologic parameters derived from DEMs, such as flow accumulation, flow direction and upslope contributing area, require that sinks be removed. This has become an accepted and common practice.

To use a DEM as a data source in hydrologic analyses, sinks must be removed, a "necessary evil" according to Burrough and McDonnell (1998) and Rieger (1998). Sinks, however, can be real components of the surface. For example in large scale data where surface hummocks and hollows are of importance to surface drainage flow, sinks are accurate features. With the advent of high resolution (submeter grid cell) DEMs it is likely that sink filling operations will be costly not 


\section{Locations of Bias Due To Sink Filling}

Subsection of Claryville, NY Quadrangle
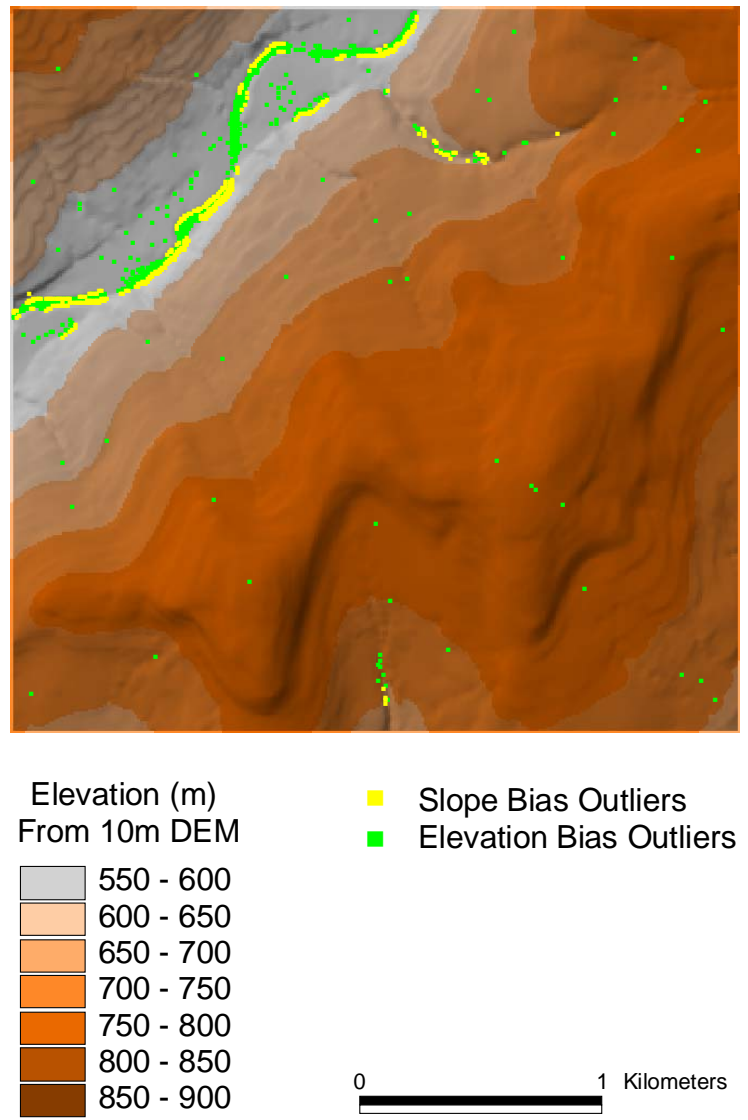

Fig. 1. Topographic locations of bias outlier points due to sink filling. Points contributing to positive elevation bias and negative slope bias were extracted from results of a Monte Carlo Simulation (elevation bias values greater than 1.61 and slope bias values less than $-3.78)$. Locations tend to coincide, falling in valley areas or locations with relatively flat slopes.

only in processing time, but in removing naturally occurring features of the terrain surface.

Naturally occurring sinks in elevation data with a grid cell size of $100 \mathrm{~m}^{2}$ or larger are rare, although they could occur in glaciated or karst topography (Mark, 1988; Tarboton et al., 1993). Rodhe and Seibert (1999) treated depressions in a $50 \times 50 \mathrm{~m}$ grid as real topographic features as part of a process to identify mires. However, generally sinks are often treated as artifacts of the DEM creation method and eliminated.

Sinks are identified by simply identifying impediments to a flow direction surface derived from a DEM. A number of methods have been described for distinguishing (Lindsay and Creed, 2006) and eliminating depressions in DEMs (Hutchinson, 1989; Jenson, 1991; Jenson and Domingue, 1988; Lindsay and Creed, 2005a; Martz and Garbrecht, 1999; O'Callaghan and Mark, 1984; Rieger, 1998).
Methods to determine whether a sink is actual, or an artifact of the DEM are time intensive. They include (a) ground inspection through field survey, (b) examination of the source data used to generate the DEM, (c) development of a classification model for a particular DEM that can be used to train the computer to recognize depressions in a particular data source, (d) knowledge-based approaches that incorporate heuristic rules specific to a data set (Lindsay and Creed, 2006).

Methods used to eliminate depressions include: (a) sink filling which raises elevations in the DEM to match surrounding cells so that flow paths can be routed, (b) breaching which lower cell elevations along a breach to route flow and (c) combinations of these approaches that both raise and lower grid cells (Lindsay and Creed, 2005a). Although an evaluation of four different methods (Lindsay and Creed, 2005a) suggests that the breaching method and a combination method are better alternatives (Lindsay and Creed, 2005a), the sink filling approach is the one most commonly found integrated into mainstream GIS software.

Sink filling is based on the D8 single flow direction flow routing method first described by Jenson and Domingue (1988) and Jenson (1991). This approach raises the sink elevation to that which enables flow linkage. The method has the disadvantage of assuming that all depressions are due to an underestimation of elevation in the sink, rather than the overestimation of surrounding cells, and flow routing is based on the D8 single-direction flow algorithm discussed previously. Other algorithms have been developed that incorporate the multiple flow path approach (Martz and Garbrecht, 1999; Rieger, 1998).

While research has focused on the development of sink filling methods, little attention has been paid to either the appropriateness of a particular sink filling algorithm or to the impact of the sink filling operation on DEMs and derived parameters. Wechsler (2000) investigated the impact of DEM errors and the sink filling procedure on representation of elevation and derived parameters using a Monte Carlo simulation technique. The effect of sink filling was quantified directly for elevation and slope and indirectly for the TI. While there was no significant difference between elevation from filled and unfilled DEMs, a significant bias was observed in the slope parameter. The sink filling procedure raised the elevation of cells where sinks were found, increasing elevations in these areas, resulting in a larger positive bias for elevation. Raising these elevations in turn decreased slope estimators in these areas, leading to negative bias for slope (Fig. 1). These findings have implications for watershed studies conducted in lower lying, flatter areas such as agricultural watersheds. Lindsay and Creed (2005) also evaluated the impact of depression filling on DEMs and derived topographic parameters and similarly concluded that depression removal significantly alters the spatial and statistical distributions of derived terrain attributes. The occurrence of depressions in remotely sensed DEMs representing varying terrain types (flat 
to mountainous) was evaluated. As would be expected, flat areas experienced more depressions than high-relief landscapes. The number of depressions found was related to grid cell resolution; coarser grids were found to be more vulnerable to depressions (Lindsay and Creed, 2005b).

In addition to the process of sink filling, hydrologists frequently undertake a method of surface modification referred to as stream burning, to generate "hydrologically enforced" DEMs (Maune, 2001). The method integrates vector representation of hydrography with the interpolation of the DEM. This automatic adjustment of the DEM has been incorporated into the ANUDEM package (Hengl et al., 2004; Hutchinson, 2006). The impact of this surface modification procedure on derived parameters has not been addressed in the literature. An advantage of this procedure is that it avoids iterative modification of the entire DEM, focusing on just the low lying stream areas. Errors could result from inconsistencies between the data sources, specifically in regard to scale.

DEMs are altered to generate surfaces over which flow can be routed to facilitate their use in further hydrologic analyses. The impact of this modification on resulting analyses bears further investigation.

\section{Distributed parameter hydrologic models}

"GIS do not 'create' information. However there appears to have developed an implicit reliance on GIS to provide information adequate to parameterize physically based distributed hydrological models, often at spatial resolution and accuracy levels that are unrealistic given the original source of spatial data." (Band and Moore, 1995, p. 419)

GISs are designed to represent environmental features, such as topography, which drive dynamic hydrologic (and other environmental) processes. Although they are not designed to serve as dynamic modeling tools (Reitsma and Albrecht, 2005) the ability of the GIS to represent the distributed nature of data sets lends itself well as a platform for integrating distributed hydrologic models.

Topography is the driving force behind the hydrologic response of a watershed. Hydrologic processes are represented by and analyzed using hydrologic models. Many hydrologic models are distributed in nature; terrain representation is divided into smaller areas or grid cells within which hydrologic processes are simulated. The raster grid structure allows flow to be routed through the watershed via grid cells. This structure integrates well with distributed parameter hydrologic models that are designed to accept grid-based inputs such as derived topographic parameters. Grid-based DEMs have been used ubiquitously to generate input parameters such as slope gradient, aspect, curvature, flow direction and upslope contributing area, for distributed parameter hydrologic models (Armstrong and Martz, 2003; Johnson and Miller, 1997; Saghafian et al., 2000).

The use of a GIS to generate input parameters for distributed parameter models enables a watershed to be ana- lyzed at higher resolutions than would be practical using manual methods. The distributing of hydrologic information imposes an inherent scale on hydrologic analyses that must be recognized. The effect of this scale is often not acknowledged and the results of the effects of this scale are neither quantified nor considered when presenting results from various hydrologic models. Sensitivity analyses are frequently performed by hydrologists on model inputs such as hydrograph estimations, and Manning's roughness coefficients. However, they are rarely performed on DEM-derived attributes such as slope, aspect and flow direction. This leads to a number of questions such as: What is the appropriate grid cell resolution for a hydrologic analysis? How does uncertainty propagate from the DEM to input parameters and through the models?

As discussed above, outputs from distributed parameter hydrologic models such as WEPP, SWAT, AGNPS and TopModel have been shown to be highly sensitive to grid cell size. Lagacherie et al. (1996) evaluated the propagation of error in topographic parameters through a hydrologic model to simulate flood events. Variations in outputs were documented and were not linear. Differences in DEM vertical accuracies were shown to impact the accuracy of runoff predictions from the soil-hydrology-vegetation model (DHSVM) (Kenward et al., 2000).

Hydrologic models are complex. Identifying sources of error in DEMs is difficult enough. Understanding their propagation to topographic parameters compounds the problem. The Generalized Likelihood Uncertainty Estimation (GLUE) method provides a mechanism for estimating uncertainty in hydrologic model predictions (Beven and Binley, 1992) and has been applied to assess uncertainty in TopModel which requires a DEM to derive input parameters (Freer et al., 1996). However, understanding, quantification and communication of how errors in numerous input parameters often required of physically-based hydrologic models affect their output continues to challenge (Beven, 2006; Beven and Binley, 1992). Practitioners often undertake hydrologic analyses with a hope that error propagation to hydrologic parameters is minimal when combined within hydrologic models. A clear cut answer is preferred over the concept of equifinality (Beven, 2006; Beven, 2007). However, is it safe to make this assumption without assessing or reporting the uncertainties associated with input parameters, especially those derived from DEMs? Research has indicated that even small discrepancies can have a meaningful impact on the results of hydrologic models, and could influence the way hydrologic information, as represented by hydrologic models is evaluated and interpreted. Users of hydrologic models must be aware of the influence that both the DEM and GIS software have on the calculation of various model parameters. The task ahead is to develop accepted methodologies for quantifying and communicating propagation of DEM errors to results of hydrologic analyses. 


\section{DEM uncertainty simulation}

DEM error and issues of specific consideration for their use in hydrologic analyses have been identified in the preceding sections. This section reviews theories associated with spatial data uncertainty and their application, and reviews how the research community has responded to quantify and represent DEM uncertainty.

\subsection{Stochastic simulation}

The "simulation school" (Chrisman, 1989) regards the map as a distribution of possible realizations within which the true values lie. Given spatial data uncertainty, a DEM can be regarded as only one rendering of a distribution of possible realizations. The stochastic simulation approach to error modeling requires a number of maps, or realizations, upon which selected statistics are performed. Uncertainty is computed by evaluating the statistics associated with the range of outputs. Representation of these equiprobable distributions of maps is referred to as stochastic modeling (Chrisman, 1989; Journel, 1996), or Monte Carlo simulation due to the random generation of uncertain variables used to simulate uncertainty.

Monte Carlo simulation assumes that the DEM is only one realization of a host of potential realizations. Each cell therefore can be represented by a probability distribution function (PDF) and each cell has a known mean and variance. A value is drawn from the PDF for each cell. This process repeated many times generating a set of realization maps (Burrough and McDonnell, 1998). In Monte Carlo analyses the outcomes represent the entire space by generating a complete probability distribution of possible outcomes (Srivasta, 1996).

Stochastic simulations provide a series of random plausible maps using stochastic modeling methods from mathematical statistics. The technique does not ensure that a "real" map is generated from the process (Chrisman, 1989), but the simulation does provide a bound within which we can state the true map lies. Simulation techniques can therefore be used to represent uncertainty about the true elevation.

Much research has focused on the use of simulation techniques to propagate error and quantify uncertainty in spatial data (see for example Brunsdon and Openshaw (1993), Deutsch and Journel (1998), Goodchild et al. (1992), Heuvelink et al. (1989), Openshaw et al. (1991), Veregin (1994)). Alternatives to Monte Carlo simulation include analytical models of error propagation based on Taylor Series expansion (see for example Albani et al. (2004), Bachmann and Allgower (2002), Heuvelink (1998), and Heuvelink et al. (1989)). However, Monte Carlo simulation is the approach commonly applied to assess DEM uncertainty regarding error propagation "... Monte Carlo methods have almost completely taken over..." (Heuvelink et al., 2007, p. 91). This can be attributed to their relative simplicity in concept, advances in computing power that have facilitated the com- putational demands of this brute force approach, and the "simplifying approximations" required of analytical methods in the face of complexity (Heuvelink et al., 2007). For the purposes of this review, selected examples of methods based on the Monte Carlo simulation approach are presented.

\subsection{Representing DEM errors by random fields}

The differences among Monte Carlo methods for simulating DEM uncertainty lie in the methods used to generate random fields. A random field ${ }^{2}$ is a surface of random values that estimates the magnitude, variance and spatial variability of uncertainty. Each value represents the potential error at a specific point (grid cell). These error maps represent the PDF of the DEM's error distribution, which accounts for the magnitude and spatial dependence of DEM error. Realizations derived from these random fields are used to quantify DEM uncertainty. The value of each cell in a random field represents one possible case from a PDF that is developed to describe what is know about a DEM's error.

The Monte Carlo simulation approach, as applied to DEMs, can be summarized as follows. a) A random field (error map) is generated based on statistical representation selected for DEM error. b) The random field is added to the original DEM resulting in a realization. c) Steps a. and b. are repeated $\mathrm{N}$ times based on the number of realizations deemed appropriate to capture the distribution of possible elevations. d) The distribution of these realizations is evaluated and uncertainty is quantified. Multiple realizations of the DEM provide a Gaussian distribution that better represents the DEM under uncertain conditions (Fisher, 1998; Hunter and Goodchild, 1997).

The underlying assumptions of the Monte Carlo simulation procedure as applied to DEM uncertainty assessment are as follows: (a) DEM error exists and constitutes uncertainty that is propagated with manipulation of the elevation data; (b) The nature and extent of these errors is unknown; c) DEM error can be represented by a distribution of DEM realizations; and d) The true elevation lies somewhere within this distribution (Wechsler, 2000; Lindsay, 2006).

Approaches to random field generation are based on two different assumptions: (a) No prior knowledge of the spatial structure of DEM error is available. Higher accuracy data can be difficult and costly to obtain. In the absence of this information, random fields can be approximated by the accuracy statistic (RMSE) provided with DEM metadata, and methods to incorporate spatial autocorrelation within

\footnotetext{
${ }^{2}$ The random function model for estimating uncertainty is rooted in the field of geostatistics and is based on an assumption of local stationarity which assumes that spatial properties are independent of location. Error is complex and is likely non-stationary, and spatially autocorrelated. The assumption of stationarity, however, applies to the search neighborhood, not the entire data set and as such is a "viable assumption even in data sets for which global stationarity is clearly inappropriate" (Isaaks and Srivasta, 1989, p. 532).
} 
these fields. (b) The second assumption is the empirical approaches which assume that the spatial structure of DEM error is available. This information can be obtained from higher accuracy data generated from ground truth surveys or other DEMs and can be integrated into random field generation.

\subsection{Estimating the parameters of random fields}

A number of methods have been presented for representing uncertainty through random fields. Simple uncorrelated random fields are normally distributed with a mean of 0 and a standard deviation often equivalent to the RMSE, which is typically the only information DEM users have about a DEM's accuracy (Hunter and Goodchild, 1997; Van Niel et al., 2004; Wechsler, 2000; Wechsler and Kroll, 2006). However, Tobler's First Law of Geography - everything is related to everything else, but near things are more related than distant things - cannot be ignored (Tobler, 1970). The uncorrelated representation of error fields as "worst case scenarios" was refuted by Oksanen (2006). Elevation is characterized by spatial dependence, or autocorrelation, therefore elevation errors are spatially autocorrelated. The nature of this autocorrelation is difficult to assess due to the complexity associated with DEM errors and potential anisotropic nature of error. However, the following methods have been developed to account for spatial autocorrelation in random fields.

Spatial moving averages apply a filter to the random field to increase its spatial autocorrelation. These filters range from $3 \times 3$ low pass filters to those that account for the distance of spatial dependence as computed by a semivariogram of the original DEM (Liu and Herrington, 1993; Wechsler and Kroll, 2006).

A process referred to as pixel swapping (Fisher, 1991; Goodchild, 1980) is based on the geostatistical concept of simulated annealing (Deutsch and Journel, 1998; Oksanen, 2006). A threshold spatial autocorrelation is identified based on properties of the input data. The spatial autocorrelation of the random field is computed. Two cells in the field are randomly identified, values in the two cells are swapped and the spatial autocorrelation recalculated. The steps are repeated until the difference between the threshold and calculated autocorrelation is within a certain threshold.

A spatial autoregressive model was presented by Hunter and Goodchild (1997). Error fields were generated using a spatially dependent disturbance term based on a spatially autoregressive process: $e=\mathbf{W} e+N(0,1)$, where e represents a vector of grid values of the disturbance field, is a parameter, and $N(0,1)$ is a vector of normally distributed random numbers (mean of 0 , standard deviation of 1 ). $\mathbf{W}$ is a matrix of weights that assigns a 1 to rook's case neighbors, and 0 otherwise. This forces to lie in the range of 0 to 0.25 (Hunter and Goodchild, 1997). The disturbance maps were simulated iteratively selecting values of $e$ and fitting them to the equation until the equation worked. Distinct patterns of autocorrelation emerged as reached values close to 0.25 .

Sequential Gaussian simulation is a geostatistical approach that assumes errors are normally distributed and their distribution can be approximated by using higher accuracy data obtained from ground control points (Aerts et al., 2003). Random fields are generated as follows: each node in the grid is visited randomly. At each node original observations and simulated nodes are selected for conditioning and kriging is used to obtain descriptive statistics of this conditional cumulative distribution function (CCDF). A random value is drawn from the CCDF and placed in that node location. The process is repeated until all locations have been populated (Journel, 1996; Oksanen, 2006).

Additional methods that require data beyond the RMSE to establish the spatial structure of DEM error have been introduced. Elschlaeger (1998) developed a method that requires higher accuracy data derived from a GPS survey or higher resolution DEM to inform the development of the random field (Ehlschlaeger, 1998; Ehlschlaeger and Shortridge, 1996; Holmes et al., 2000). This three-parametermethod creates random fields with a Gaussian distribution that matches the mean and standard deviation parameters derived from a "difference map". Spatial autocorrelative characteristics of spatially dependent uncertainty are accounted for in the algorithm. This method improves upon the pixel swapping and spatial autoregressive approaches which allow only one parameter to define the structure of the error model (Ehlschlaeger, 1998; Oksanen, 2006).

Kyriakidis et al. (1999) present a geostatistical method that is based on a combination of sparsely available higher accuracy ("hard" data) with given DEM elevations ("soft" data). Elevation realizations are generated by cokriging and are based on auto- and cross-covariance models that quantify the autocorrelation and cross-correlation between the hard and soft data (Kyriakidis et al., 1999; Oksanen, 2006) .

\subsection{DEM Error Simulation: Case Studies}

“...there is no inherent reason why conditional simulation should not be used as routinely for uncertainty analysis as kriging is used for interpolation. It is unlikely, however, that conditional simulation will become available in the GIS environment until a substantial demand has been established...this is likely to require the gradual accumulation of case studies in the literature..." (Englund, 1993 p. 437).

Each of the following case studies demonstrates the applicability of the Monte Carlo simulation approach to error propagation and uncertainty assessment in DEMs and DEM-derived data. These studies establish that progress has been made in demonstrating the applicability and effectiveness of these approaches to error propagation within a Monte Carlo Simulation. However the varied error propagation approaches indicate that an agreed approach is as of yet unresolved. The remaining challenge is to provide 
10 Meter Grids

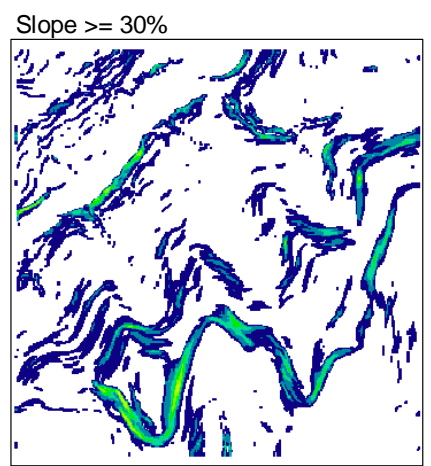

Probability [U $10 \mathrm{~m}$ ]

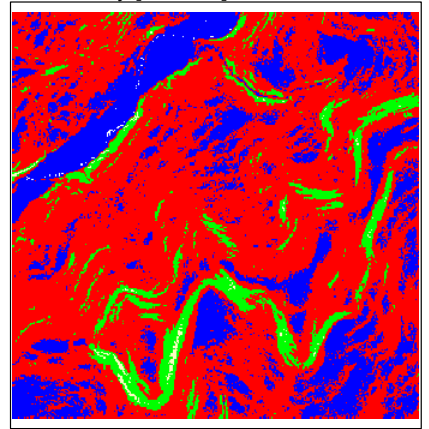

Probability [W $10 \mathrm{~m}]$

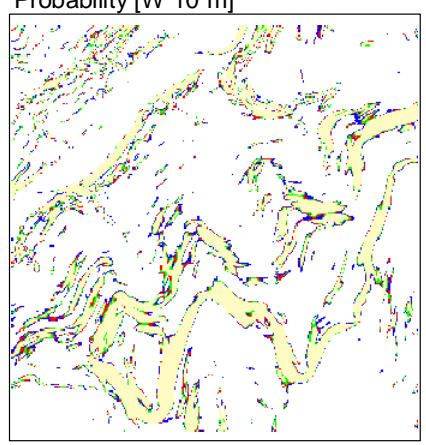

30 Meter Grids

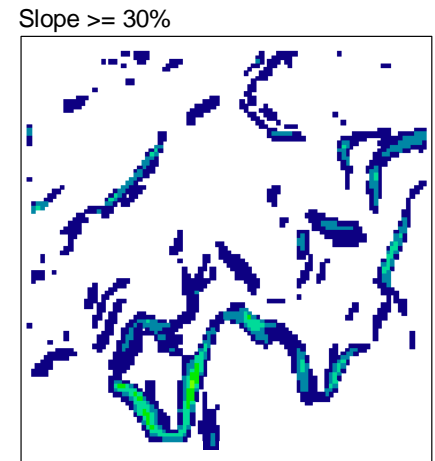

Probability [U $30 \mathrm{~m}$ ]

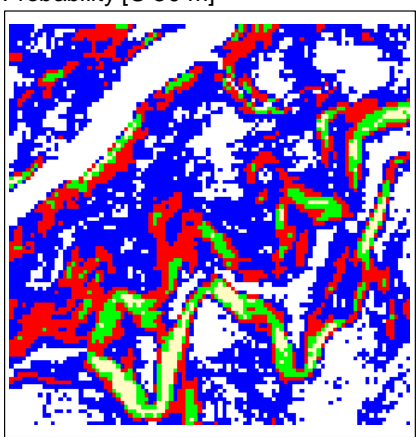

Probability [W $30 \mathrm{~m}]$

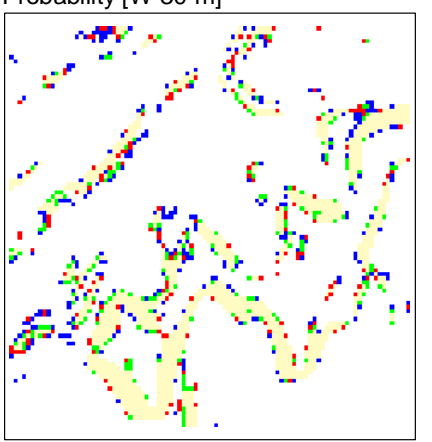

\section{Probability of \\ Exceeding \\ Threshold}

\section{Slope \\ $>=\mathbf{3 0} \%$}

Slope $\%$

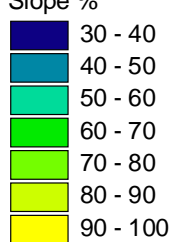

Probability (\%)

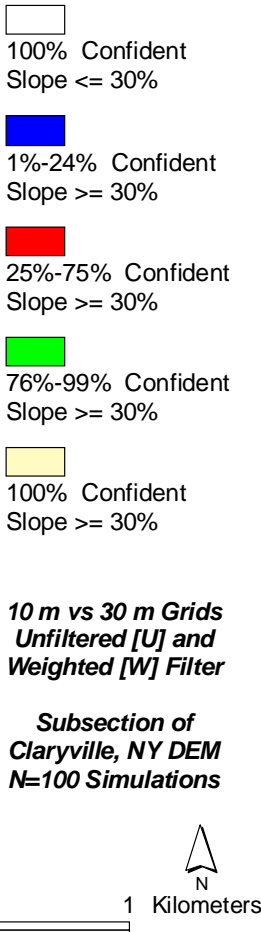

Fig. 2. Results of a Monte Carlo simulation demonstrating the probability that slopes will be $>=30 \%$. Two methods for generating random fields were used: $\mathrm{U}$ corresponds to uncorrelated random fields and $\mathrm{W}$ represents spatially autocorrelated random fields. The results demonstrate the effects of uncertainty using two different random field methods and grid cell resolutions (10 and $30 \mathrm{~m})$.

these approaches as tools that DEM users can readily access through GIS software packages. There will be occasions when a DEM user has access to a higher accuracy data source for generating information on the spatial structure of error, and there will be occasions when that information is unavailable.

\subsubsection{Higher accuracy data unavailable}

The following studies incorporate either the RMSE statistic for a particular DEM or expert judgment regarding development of the error fields.
The Pixel swapping algorithm presented by Goodchild (1980) has been applied in a number of studies. Lee et al. (1992) found that floodplain delineations were significantly affected by DEM error. Fisher (1993) simulated the impact of DEM error on viewshed analyses using this method and determined that DEM-derived viewsheds may overestimate representation of the "true" viewshed. Davis and Keller (1997) modified the Goodchild (1980) approach to model uncertainty in slope stability prediction. The modified method was used to increase spatial autocorrelation in error field generated by variogram analyses. The authors suggested that this method could be improved by incorporating autocorrelation 
at different levels of aggregation based on slope classes, user defined windows or slopes. The Goodchild (1980) method was also adapted by Veregin (1997) to incorporate slope in the iterative swapping approach. In this approach, slope served as an underlying indicator of the spatial distribution of DEM error. Flow paths derived from DEMS using the D8 method were found to be sensitive to DEM errors, especially in areas of low slope. Murillo and Hunter (1997) applied the spatially autocorrelation iterative swapping method to evaluate the effect of DEM error on prediction of areas susceptible to landslides. While uncertainty associated with some model input such as choice of slope classes and slope algorithms were acknowledged the impact of these uncertainties was not assessed. Uncertainty results were communicated through visualization via map output. Lindsay (2006) applied this approach to assess the impact of DEM error on six methods for extracting channel networks from a DEM. Methods that required identification of patterns from surface morphology (valley-recognition algorithms) were more sensitive than channel-initiation techniques, perhaps because elevation error was shown to influence positioning of channel heads and links (Lindsay, 2006).

Hunter and Goodchild (1997) applied a spatially autoregressive random field method that incorporates spatial autocorrelation of DEM error. This method was compared with completely random, uncorrelated error fields to assess the effect of these error representations on slope and aspect calculations. The authors concluded that an error model ought to be based on an assumption of spatial dependence of error; however, completely random fields could be applied in the absence of a higher accuracy surface from which to obtain this information.

Wechsler (2000) and Wechsler and Kroll (2006) compared simulations resulting from four different methods of random fields that included completely random (mean of 0 and standard deviation equal to the RMSE) and three different filter methods that increased the spatial autocorrelation of the error fields. Wechsler (2000) applied this method to evaluate the effects of DEM uncertainty on sink filling, topographic parameters calculated at different resolutions, and topographic parameters computed for different terrain types (Figs. 2 and 3). Although less sophisticated than the iterative swapping method to achieving spatial autocorrelation, the methodology was implemented directly via an extension to a commonly used GIS software package.

Widayati et al. (2004) implemented the error propagation methods presented by Wechsler (2000) to evaluate the propagation of elevation error on flat and varied slopes and differing grid resolutions. Slope error was found to be sensitive to the spatial dependence of DEM error. Cowell and Zeng (2003) assessed uncertainty in the prediction of coastal hazards due to climate change. Uncertainty in the DEM was represented by random, normally distributed error fields. As error was increased, model output uncertainty decreased due to the nature of the normal distribution of the error fields used.

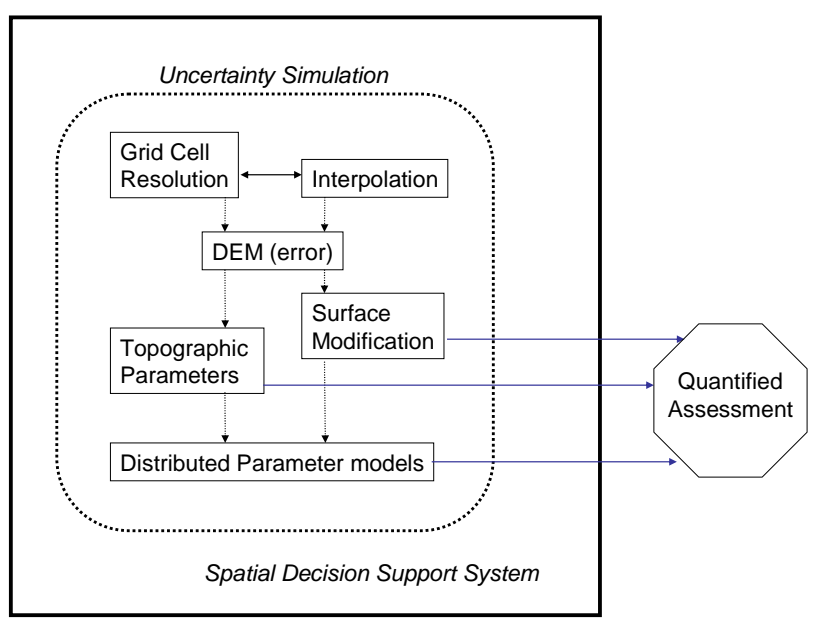

Fig. 3. Spatial model of a DEM uncertainty SDSS toolbox.

Yilmaz et al. (2004) simulated DEM error using completely random fields with a normal distribution based on the RMSE to demonstrate the impact of DEM uncertainty on the results of a flood inundation model.

More recently, a "process convolution" or spatial moving averages approach to the generation of random error fields was used to evaluate the delineation of drainage basins that were found to be very sensitive to DEM uncertainty (Oksanen and Sarjakoski, 2005a; Oksanen and Sarjakoski, 2006). The approach was applied to both slope and aspect derivatives and demonstrated that completely random uncorrelated random error fields are not a valid mechanism for representing DEM error (Oksanen and Sarjakoski, 2005b; Oksanen and Sarjakoski, 2006).

Methods for assessing DEM uncertainty through simulation and error propagation have not been fully integrated into assessing hydrologic model output with the exception of Zerger (2002) who investigated the effect of DEM uncertainty on a storm surge model. Random error fields were spatially autocorrelated. DEM errors impacted low inundation scenarios. This spatial uncertainty was communicated using visualization through risk maps.

\subsubsection{Higher accuracy data available}

Another school of thought on error propagation assumes that the RMSE alone is an insufficient indicator of DEM error, and that additional knowledge of the spatial structure of error in a particular DEM is required for uncertainty modeling in a Monte Carlo simulation. Approaches have been developed that incorporate higher accuracy data, such as that garnered from a higher accuracy DEM or GPS survey, to develop a model of the spatial structure of error, which in turn is used to generate DEM realizations.

Ehlschlaeger and Shortridge (1996) developed a model that creates random fields with a Gaussian distribution that 
matches the mean and standard deviation derived from a higher accuracy data source. Spatial autocorrelative characteristics of spatially dependent uncertainty are accounted for in the algorithm that was applied to a least-cost-path application. Kiriakidis et al. (1999) present a geostatistical approach to DEM realizations that incorporate autocorrelation information derived from residuals obtained from higher accuracy sources. Holmes et al. (2000) applied this approach to the prediction of slope failure. Endreny and Wood (2001) evaluated the effect of DEM error on flow dispersal area predictions using six different algorithms. Error fields were spatially autocorrelated based on an error matrix derived from an assessment of differences between the test USGS $30 \mathrm{~m}$ DEM and a higher resolution $10 \mathrm{~m}$ SPOT DEM. Uncertainty results were communicated using probability maps. Ehlschlaeger (2002) introduced a method for generating error fields that accounts for both the spatial autocorrelation of error and incorporates information about DEM characteristics such as topological shapes in the error model. Canters et al. (2002) evaluated the effects of DEM error on a landscape classification model. Random error fields were spatially correlated using error characteristics derived from a ground truth survey. While uncertainty caused by image classification was found to be more significant than DEM error, transition zones were particularly sensitive to DEM error. Van Niel et al. (2004) applied Monte Carlo simulation to assess the impact of DEM uncertainty on slope, aspect, net solar radiation, topographic position and topographic index. The error in these DEMderived parameters was propagated to results of a vegetation model. DEM error was assessed by comparison with a higher accuracy data source obtained from a GPS survey and used to filter normally distributed random error fields.

\section{Integrating and communicating DEM uncertainty}

“...The absence of facilities within GIS software for handling the effects of input data uncertainty and possible error propagation by GIS operations creates a question mark over the safe utilization of many aspects of the technology..." (Openshaw et al., 1991, p. 78)

Methods have been developed that transfer information from a GIS into external error propagation analysis tools (see for example Heuvelink (1998), Hwang et al. (1998)). Output from these external systems is either returned to the GIS for mapping and visualization or exported to graphic charts or statistical tables (Hwang et al., 1998). Attempts have also been made to integrate uncertainty simulation tools within a GIS (Wechsler, 2000). However, a viable DEM uncertainty toolbox that incorporates various simulation approaches, and considers the fundamental areas that contribute to DEM uncertainty described herein has not yet been realized. What are the essential components of a viable DEM uncertainty toolbox and what form should it take? How should simulation results be quantified and communicated?

\subsection{User interfaces: decision support systems}

Assessment of the multiple factors that contribute to DEM uncertainty and their propagation to topographic parameters and hydrologic models is complex. The ability of a user to interact with and explore possible outcomes is crucial for informed decision making. Spatial decision support systems (SDSS) provide a mechanism for integrating data exploration and assessing model outcome to facilitate informed decision making and can serve as a mechanism for achieving this interaction with DEM users. An SDSS is generally comprised of a spatial database and a user-defined interface that accesses GIS analysis and modeling capabilities. Multiple Criteria Decision Models (MCDM) are a type of SDSS that allow users to make decisions with multiple alternatives (Ascough et al., 2002; Jankowski et al., 2001).

Current GIS interfaces provide limited support for spatial data exploration and uncertainty assessment. However, many GIS user interfaces can now be modified and enhanced through object-oriented programming that allows users to develop tools to assess model results and assist in decision making based on these results. Such direct integration of decision support tools that incorporate uncertainty theory within a GIS has been achieved on a limited basis. Wechsler (2000) and Wechsler and Kroll (2006) integrated a toolbox within a GIS to allow users to simulate the effects of DEM error on elevation, slope, upslope area and the topographic index. While results were not carried through to a particular hydrologic modeling effort, and used simple error propagation techniques, the approach demonstrated how these tools can be integrated as pull-down-menus into mainstream GIS. Aerts et al. (2003) developed an SDSS external to a GIS to assess the impact of DEM uncertainty on a cost-path analysis for ski run development. Although uncertainty associated with specific model input parameters such as slope cannot be culled out, and the product is not specifically part of a GIS package, the research successfully demonstrates the efficacy of such an approach. Gunther (2003) developed a software program called SLOPEMAP, that integrates with two commonly used terrain analysis packages (ArcView GIS and Surfer) to derive geologic information from a DEM for assessment of rockslide susceptibility. Debruin and deWit (2005) developed a method to streamline the evaluation of grids within a stochastic simulation. This computer application demonstrates progress in the use of Monte Carlo simulations on desktop computers. Currently some GIS packages have limitations on the number of grids that can be assessed simultaneously. Other GIS-based decision support tools have been developed. Wise et al. (2001) report on the results of the successful integration of a GIS-based user interface for statistical spatial data analysis. Durañona and Lopez (2000) developed a toolbar to detect errors in a DEM. Crosetto and Tarantola (2001) present general procedures for assessment of uncertainty within a GIS-based flood forecasting model. Karssenberg and DeJong (2005) describe concepts 
for integrating error propagation functionality based on existing concepts within an environmental modeling language. They concede that a consistent framework for implementing error propagation into environmental modeling has not been achieved and suggest that this is because tools are not available or accessible for a wide range of users (Karssenberg and Jong, 2005).

Each of these studies demonstrates the viability of the SDSS as a mechanism for addressing DEM uncertainty, and integrating that knowledge with specific distributed parameter hydrologic models. There is as of yet no consensus about how to present these tools and to communicate results of uncertainty assessments. Visualization of the results of error propagation could be a mechanism for increasing their accessibility.

\subsection{Visualization}

"A number of visualization tools need to be developed to portray error at the same time as the original data. The increasing use of computer displays and the development of stochastic models of error present the opportunity for doing just this." (Fisher, 1994 p. 181).

Results of methods to assess DEM uncertainty must be effectively communicated in order to be integrated and applied. Cartographic representations are the primary method of communicating results from GIS-based spatial analyses, and the main communicative output provided by GISs. DEM uncertainty can be visualized in a number of ways including static tables or graphs, error maps of residuals between a DEM and a higher accuracy data source, error matrices, static maps or map animations of realizations from Monte Carlo Simulations (Davis and Keller, 1997; Ehlschlaeger, 1998; Ehlschlaeger et al., 1997; Wood, 1996). Other efforts have integrated tools within the GIS interface. This section discusses progress in these areas.

Visualization techniques have been applied to evaluate and convey the potential inaccuracies inherent in DEM data sets such as DEM error (Acevedo, 1991), interpolation accuracy (Wood, 1996; Wood and Fisher, 1993) and results of DEM uncertainty simulations (Hunter and Goodchild, 1995). Spear et al. (1996) conducted a survey to investigate the effectiveness of different visualization techniques in conveying DEM interpolation uncertainty. Map animations have been used to visualize uncertainty in image classification (Zhang and Stuart, 2001) and a slope stability model Davis and Keller (1997). Jankowski et al. (2001) investigated the role of maps as visual tools in the data exploration and decision making process. A user interface was developed that allows users to interactively visualize the results of certain input assumptions. While a DEM was not part of this particular analysis, the approach could be followed to develop methods to assess DEM uncertainty.

Visualization of uncertainty alone may not be an efficient method for communicating uncertainty to the deci- sion maker. Quantitative estimates of error and their consequences, if available, should be either incorporated into the visualization or reported. What should a hydrologicallybased DEM uncertainty SDSS toolbox look like and how should results be communicated? Research and technology demonstrate that the integration of simulation research with hydrologic models is possible. Cartographic research continues to focus on communication approaches. Distributed hydrologic models vary extensively and therefore uncertainty results will vary based on the distributed model applied. A modular DEM error assessment system would be capable of breaking up the component uncertainties and assessing the impact of error on model outputs (see for example Fig. 3). For such a system to be successful, continued research is required to assess the human component, to determine to what extent and in what format users are willing to accept, address and manage error.

\subsection{DEM uncertainty toolbox}

DEM uncertainty simulation methodologies have been developed and some assessments of the effect of DEM uncertainty on specific hydrologic models have been evaluated in case studies. Although progress has been made, these approaches are far from being implemented as a spatial decision support system for DEM users. The paradigm of an "uncertainty button" (Goodchild et al., 1999) or uncertainty toolbox provided by vendors and implemented by users is not yet a reality. Yet is such an invention even a viable option? Sentiment has been expressed that due to the complexity of the topic, an uncertainty toolbox is a fantasy. Uncertainty assessment is thought to require too much processing time and considerable prior knowledge is required of the DEM users (Heuvelink, 2002). DEM users are not likely to be willing to spend time on uncertainty assessment (Wechsler, 2003) unless it becomes a simplified and cost-effective exercise that can be justified in 'billable hours'.

The call for a DEM uncertainty toolbox echoes that of previous researchers and the GIS community. This has not yet been satisfactorily achieved in the decade-or-so since it was first suggested, probably due to a combination of technology limitations, software limitations and DEM user limitations. However, as a discipline, the hydrologic GIS user community is ready to progress in this area. Technology limitations are continuing to be overcome; computer processing power has increased and Monte Carlo simulations on raster grids can now be performed on most desktop computers.

Ultimately, a DEM uncertainty toolbox would provide a mechanism for users to simulate the effect of DEM error (whether higher accuracy data is available, or not) derive a series of plausible outcomes for particular distributed parameter hydrologic models, and communicate model results visually and quantitatively given DEM uncertainty. Perhaps once these buttons become part of the DEM processing toolbox, users may become more receptive to using an SDSS that 
allows users to simulate DEM uncertainty and incorporate uncertainty output into analytical results that inform decision makers with greater accuracy.

\section{Conclusions}

While not exhaustive, this review presents key research issues associated with DEMs as applied to hydrologic applications. A central focus is on DEM uncertainty that affects the use of DEMs for hydrologic applications. The review documents that DEM error, topographic parameter generation, grid cell resolution, and hydrologic modifications are all essential considerations when undertaking an assessment and quantification of DEM uncertainty. These variables, conditions and problems should be considered for the development of an uncertainty toolbox.

The GIS community continues to move forward in providing and using mechanisms for addressing DEM uncertainty and its propagation through hydrologic analyses. Further progress will require intellectual leadership resulting in collaboration and commitment from the GIS stakeholders including researchers, software developers, data vendors, educators and practitioners.

In the course of this review research questions have been identified and recommendations have been made throughout. Specific recommendations are reiterated here and grouped by the entities who should lead the efforts. However, success will require feedback loops among and between these groups. The collaboration among stakeholders might begin with establishing a long term study group that is charged with designing components for a DEM uncertainty toolbox.

\subsection{Recommendations for research}

In mature sciences, the scientific community tends to agree about instruments and procedures for measurement. Science requires reliable, veridical measurements and procedures. Our knowledge of the world depends on the quality of this scientific framework and is continually being expanded by digital data and capabilities of geographic information systems. Geographic Information Science is on its way to becoming a mature science. To achieve this goal we must incorporate discipline and consistency in the use of digital data. Standards should be developed to address the level of error appropriate for specific applications. These standards will guide the GIS community in addressing and reporting the impact of DEM uncertainty. The following recommendations are some steps that can be taken.

- Refine and continue to develop appropriate methods for quantifying, simulating and communicating DEM uncertainty.

- Develop methods to take advantage of subgrid information that is lost when DEMs are aggregated from high accuracy point data, and identify the sources of error contributed by interpolation algorithms. This information could become a useful component for DEM uncertainty estimations (Section 2.0).

- Identify appropriateness of algorithms for deriving topographic parameters given grid cell resolutions and topographic complexity. Modifications to the raster grid cell structure could accommodate varied topography and provide a more appropriate representation of terrain surfaces for hydrologic applications (Sections 3.0 and 4.0).

- Identify essential components of a viable DEM uncertainty toolbox and what form the SDSS should take to simulate, quantify and communicate results. This will involve assessment of the "human factors" component, to determine to what extent and in what format users are willing to accept, address and manage error.

- Develop methods to quantify the impact of surface modification (i.e. sink filling and stream burning) and integrate these into the uncertainty toolbox (Section 5.0)

\subsection{Recommendations for software and data developers}

Software developers and vendors are in the position to implement a paradigm shift in the way users respond to and interact with spatial data. Once error-enhancements are made to the typical GIS interface, users will become more receptive to uncertainty in spatial data and the incorporation of measures to quantify it in analytical results. This will ultimately inform decision makers with greater accuracy. The following recommendations are expected to enable the user community become more aware of and receptive to recognizing and accommodating spatial data uncertainty.

- The varied error propagation approaches reviewed demonstrate a variety of approaches for propagating DEM uncertainty. This family of simulation approaches should be integrated into a DEM uncertainty toolbox to provide mechanisms for a wide range of users to simulate the effect of DEM error whether higher accuracy data is available, or not (Sect. 7).

- DEM uncertainty assessment and quantification requires information on the spatial structure of DEM error. DEM data developers should provide additional information so that methods programmed in the uncertainty toolbox can more appropriately reflect the spatial structure of error (Sect. 2.3).

- GIS software interfaces should provide users with choices in approaches to deriving parameters frequently used in hydrologic analyses (Sect. 3). This will yield "smarter" GISs that are capable of evaluating a DEM, and then apply an appropriate algorithm to specific 
areas based on terrain characteristics and complexity (Sect. 3).

- Develop a "smarter" GIS that can sense differentiation in terrain complexity. Specific grid cell resolutions and terrain attribute algorithms could be applied based on terrain complexity, rather than taking a "one size fits all" approach (Sect. 4).

- Develop data exploration methods to assist users in selecting an appropriate grid cell resolution when interpolating or aggregating data for DEM production. Users could either choose a resolution or select one that has been "suggested" by behind-the scene computations and data exploration in the intelligent GIS (Sect. 2).

- Model-specific solutions would enable users to derive a series of plausible outcomes for particular distributed parameter hydrologic models, and communicate model results visually and quantitatively given DEM uncertainty (Sect. 6).

- Work with researchers and educators to develop the DEM uncertainty toolbox. This will require determination of the components pf the pull-down menus, and the integration of interactive cartographic representations to enable users to visualize impacts of DEM uncertainty (Sect. 8.2).

\subsection{Recommendations for educators and students}

The software, research and education communities should not be hindered by the concern that users of spatial information are "frightened" by mathematical equations and do not have sufficient background in statistics to be responsible users of error propagation tools (Heuvelik, 2007, p. 94). GIS is ubiquitous, however most of its practitioners not likely to be trained in the underlying mathematics of topological relationships and other sophisticated underlying GIS components. The users of the DEM uncertainty toolbox would likely be specialized (like users of ESRI's Geostatistical Analyst or Statistical Analyst tools). These users are likely to be interested in, and able to manage and understand the concepts and requirements of error propagation. With education and commitment the expressed futility regarding our progress to date (Heuvelink 2002, Heuvelink, 2007) due to the complexity of the issues can be overcome.

- The perception of uncertainty and error as "bad" must be altered. Educators should assert that the concept of error is a fact of spatial data that must and can be acknowledged and addressed (Sect. 2).

- Educators can raise awareness of uncertainty by training students to access and incorporate the enhanced options provided by software developers, such as different algorithms for computing topographic parameters.
- Once these options are integrated into mainstream GIS, users will become more receptive to the concept of multiple plausible answers to an analysis rather than one grid as the correct derivative from a DEM. This is an important first step in educating a user community that is receptive to alternative realizations. This community will then be primed to accept and apply a DEM uncertainty toolbox.

- Practitioners should be helped to understand the extent of error that is present and offered assistance in managing that error. Consumers of derived analytical results must understand the consequences of their measures so that they can make informed choices.

Research is only as good as its tools. The keepers of knowledge and technology have the responsibility to apply their resources at the most competent level possible, while acknowledging limitations. The problem of error is central in all scientific endeavors. One tenet of the scientific methods is to push the boundaries of "truth" by sharpening tools and reducing error. Therefore all stakeholders in the GIS community must be willing to take stands and act appropriately in relation to error. The error of our measures should be scientifically and ethically acceptable for the purposes that these measures are applied. The challenge is to create mechanisms to fulfill this responsibility.

Acknowledgements. This document was greatly improved by the detailed comments and thoughtful input provided by two anonymous reviewers and $\mathrm{H}$. Perlitsh. I would like to express gratitude to E. van Loon for providing the opportunity to develop this article.

Edited by: E. van Loon

\section{References}

Acevedo, W.: First Assessment of U.S. Geological Survey 30Minute DEMs: A Great Improvement over Existing 1-Degree Data, ASPRS-ACSM Technical Papers, 2, 1-14, 1991.

Aerts, J., Goodchild, M., and Heuvelink, G. B. M.: Accounting for spatial uncertainty in optimization with spatial decision support systems, Transactions in GIS, 7, 211-230, 2003.

Airborne1: LiDAR Accuracy An Airborne1 Perspective, Briefing Note BN\#01, Airborne1 Corporation, El Segundo, CA, 2006.

Albani, M., Klinkenberg, B., Andison, D. W., and Kkimmins, J. P.: The choice of window size in approximating topographic surfaces from Digital Elevation Models, Int. J. Geogr. Inf. Sci, 18, 577-593, 2004.

Armstrong, R. N. and Martz, L. W.: Topographic Parameterization in continental hydrology: a study in scale, Hydrol. Processes, 17, 3763-3781, 2003.

Ascough, J. C., Rector, H. D., Hoag, D. L., McMaster, G. S., Vandenberg, B. C., Shaffer, M. J., Weltz, M. A., and Ahjua, L. R.: Multicriteria Spatial Decision Support Systems: Overview, 
Applications, and Future Research Directions. Integrated Assessment and Decision Support Proceedings of the 1st Biennial Meeting of the IEMSs, Lugano, Switzerland 3, 175-180, 2002.

Bachmann, A. and Allgower, B.: Uncertainty propagation in wildland fire behaviour modelling, Int. J. Geogr. Inf. Sci, 16, 115127, 2002.

Band, L. and Moore, I.: Scale: Landscape Attributes And Geographical Information Systems, Hydrol. Processes, 9, 401-422, 1995.

Berry, P. A. M., Hoogerboord, A. M., and Pinnock, R. A.: Identification of Common Error Signatures in Global Digital Elevation Models Based on Satellite Altimeter Reference Data, Phys. Chem. Earth (A), 25, 95-99, 2000.

Beven, K.: A manifesto for the equifinality thesis, J. Hydrol., 320, 18-36, 2006.

Beven, K.: Towards integrated environmental models of everywhere: uncertainty, data and modelling as a learning process, Hydrol. Earth Syst. Sci., 11, 460-467, 2007,

http://www.hydrol-earth-syst-sci.net/11/460/2007/.

Beven, K. and Binley, A.: The Future of Distributed Modeling: Model Calibration and Uncertainty Prediction, Hydrol. Processes, 6, 255-264, 1992.

Bolstad, P. and Stowe, T.: An Evaluation of DEM Accuracy: Elevation, Slope, and Aspect, Photogramm. Eng. Rem. S., 60, 13271332, 1994.

Brasington, K. and Richards, K.: Interactions Between Model Predictions, Parameters and DTM Scales for TopModel, Comput. Geosci., 24, 299-314, 1998.

Brunsdon, C. and Openshaw, S.: Chapter 7: Simulating the effects of error in GIS, in: Geographical Information Handling - Research and Applications, edited by: Mather, P., John Wiley and Sons, New York, 47-61, 1993.

Burrough, P. and McDonnell, R.: Principles of Geographic Information Systems, Oxford University Press, New York, NY, 333 p., 1998.

Burrough, P. A.: Principles of Geographical Information Systems for Land Resources Assessment, Oxford University Press, New York, NY, 194 p., 1986.

Canters, F., DeGenst, W., and Dufourmont, H.: Assessing effects of input uncertainty in structural landscape classification, Int. J. Geogr. Inf. Sci, 16, 129-149, 2002.

Carter, J.: Some Effects of Spatial Resolution in the Calculation of Slope Using the Spatial Derivative, ASPRS-ACSM Annual Convention - Technical Papers, 1, 43-52, 1990.

Chang, K.-T. and Tsai, B.-W.: The effect of DEM Resolution on Slope and Aspect Mapping, Cartography and GIS, 18, 67-99, 1991.

Chaplot, V.: Impact of DEM mesh size and soil map scale on SWAT runoff, sediment, and NO3-N loads predictions, J. Hydrol., 312, 207-222, 2005.

Chaubey, I., Cotter, A. S., Costello, T. A., and Soerens, T. S.: Effect of DEM data resolution on SWAT output uncertainty, Hydrol. Processes, 19, 621-628, 2005.

Chochrane, T. A. and Flanagan, D. C.: Effect of DEM Resolutions in the runoff and soil loss predictions of the WEPP watershed model, Transactions of the ASAE, 48, 109-120, 2005.

Chrisman, N.: Error in Categorical Maps: Testing versus Simulation. Auto-Carto 9: Proceedings of the 9th International Symposium on Computer-Assisted Cartography, ASPRS/ACSM, Balti- more, Maryland, 521-529, 1989.

Claessens, L., Heuvelink, G. B. M., Schoorl, J. M., and Veldkamp, A.: DEM resolution effects on shallow landslide hazard and soil redistribution modelling, Earth Surf. Proc. Land., 30, 461-477, 2005.

Costa-Cabral, M. and Burgess, S.: Digital Elevation Model Networks (DEMON): A model of flow over hillslopes for computation of contributing and dispersal areas, Water Resour. Res., 30, 681-1692, 1994.

Cowell, P. and Zeng, T.: Integrating uncertainty theories with GIS for modeling coastal hazards of climate change, Mar. Geod., 26, 5-18, 2003.

Crosetto, M. and Tarantola, S.: Uncertainty and sensitivity analysis: tools for GIS-based model implementation, Int. J. Geogr. Inf. Sci, 15, 415-437, 2001.

Davis, T. J. and Keller, C. P.: Modeling and Visualizing Multiple Spatial Uncertainties, Comput. Geosci., 23, 397-408, 1997.

deBruin, S. and deWit, A. J. W.: Stochastic simulation of large grids using free and public domain software, Comput. Geosci., 31, 828-836, 2005.

Desmet, P. and Govers, G.: Comparison of routing algorithms for digital elevation models and their implications for predicting ephemeral gullies, Int. J. Geogr. Inf. Syst., 10, 311-331, 1996.

Desmet, P. J. J.: Effects of Interpolation Errors on the Analysis of DEMs, Earth Surf. Proc. Land., 22, 563-580, 1997.

Deutsch, C. and Journel, A.: GSLIB Geostatistical Software Library and User's Guide, Oxford University Press, New York, 369 p., 1998.

Dubois, G., Malczewski, J., and Cort, M. D.: Spatial Interpolation Comparison 97: Special Issue, Journal of Geographic Information and Decision Analysis, 2, Special Issue, 1998.

Dunn, M. and Hickey, R.: The effect of slope algorithms on slope estimates within a GIS, Cartography, 27, 9-15, 1998.

Durañona, G. and López, C.: DM4DEM: a GRASS-compatible tool for blunder detection of DEM, 4th International Symposium on Spatial Accuracy Assessment in Natural Resources and Environmental Sciences, Amsterdam, The Netherlands, 191-194, 2000.

Eastman, R.: Idrisi, Clark University Graduate School of Geography, Worcester, MA, 1992.

Ehlschlaeger, C.: The Stochastic Simulation Approach: Tools for Representing Spatial Application Uncertainty, University of California Santa Barbara, Santa Barbara, CA, Ph.D. Dissertation, 1998.

Ehlschlaeger, C. and Shortridge, A.: Modeling Elevation Uncertainty in Geographical Analyses, Proceedings of the International Symposium on Spatial Data Handling, Delft, Netherlands, 9B.15-19B.25, 1996.

Ehlschlaeger, C. R.: Representing multiple spatial statistics in generalized elevation uncertainty models: moving beyond the variogram, Int. J. Geogr. Inf. Sci, 16, 259-285, 2002.

Ehlschlaeger, C. R., Shortridge, A. M., and Goodchild, M. F.: Visualizing Spatial Data Uncertainty Using Animation, Comput. Geosci., 23, 387-395, 1997.

Endreny, T. A. and Wood, E. F.: Representing elevation uncertainty in runoff modelling and flowpath mapping, Hydrol. Processes, 15, 2223-2236, 2001.

Englund, E.: Spatial Simulation: Environmental Applications, Chapter 43, in: Environmental Modeling with GIS, edited by: Goodchild, M., Parks, B., and Steyaert, L., Oxford University 
Press, New York, 432-446, 1993.

Erxleben, J., Elder, K., and Davis, R.: Comparison of spatial interpolation methods for estimating snow distribution in the Colorado Rocky Mountains, Hydrol. Processes, 16, 3627-3649, 2002.

ESRI: ArcView Spatial Analyst, Environmental Systems Research Institute, Redlands, CA, 1998.

Evans, I.: What Do Terrain Statistics Really Mean?, in: Landform Monitoring, Modelling and Analysis, edited by: Lane, S. N., Richards, K. S., and Chandler, J. H., John Wiley and Sons, New York, 300 p., 1998.

FGDC: Geospatial Positioning Accuracy Standards Part 3: National Standard for Spatial Data Accuracy, FGDC-STC-007.31998, USGS Federal Geographic Data Committee, 25 pp., 1998.

Fisher, P.: Algorithm and Implementation Uncertainty in Viewshed Analysis, Int. J. Geogr. Inf. Sci., 7, 331-347, 1993.

Fisher, P.: Animation and Sound For the Visualization of Uncertain Spatial Information, Chapter 19, in: Visualization In Geographical Information Systems, edited by: Hearnshaw, H. and Unwin, D., John Wiley and Sons, 181-185, 1994.

Fisher, P.: Sorites paradox and vague geographies, Fuzzy Set Syst., 113, 7-18, 2000.

Fisher, P. F.: First experiments in viewshed uncertainty: the accuracy of the viewshed area, Photogramm. Eng. Rem. S., 57, 13211327, 1991.

Fisher, P. F.: Improved Modeling of Elevation Error with Geostatistics, GeoInformatica, 2, 215-233, 1998.

Freer, J., Beven, K., and Ambroise, B.: Bayesian estimation of uncertainty in runoff prediction and the value of data: An application of the GLUE approach, Water Resour. Res., 32, 2161-2174 1996.

Gao, J.: Resolution and Accuracy of Terrain Representation by Grid DEMs at a micro-scale, Int. J. Geogr. Inf. Sci, 11, 199-212, 1997.

Garbrecht, J. and Martz, L.: Grid Size Dependency Of Parameters Extracted From Digital Elevation Models, Comput. Geosci., 20, 85-87, 1994.

Goodchild, M.: Algorthm 9: Simulation of autocorrelation for aggregate data, Environ. Plann. A., 12, 1073-1081, 1980.

Goodchild, M., Shortridge, A., and Fohl, P.: Encapsulating Simulation Models with Geospatial Data Sets, in: Spatial Accuracy Assessment: Land Information Uncertainty in Natural Resources, edited by: Lowell, K. and Jaton, A., Ann Arbor Press, Ann Arbor, Michigan, 1999.

Goodchild, M., Sun, G., and Yang, S.: Development and Test of an Error Model for Categorical Data, Int. J. Geogr. Inf. Syst., 6, 87-104, 1992.

Gunther, A.: SLOPEMAP: programs for automated mapping of geometrical and kinematical properties of hard rock hill slopes, Comput. Geosci., 29, 865-875, 2003.

Guth, P. L.: Slope and aspect calculations on gridded digital elevation models: Examples form a geomorphic toolbox for personal computers, Z. Geomorph, N. F., Suppl. 101, 31-52, 1995.

Hancock, G. R.: The use of digital elevation models in the identification and characterization of catchments over different grid scales, Hydrol. Processes, 19, 1727-1749, 2005.

Hengl, T., Gruber, S., and Shrestha, D. P.: Reduction of errors in digital terrain parameters used in soil-landscape modelling, Int. J. Appl. Earth Obs. Geoinfo., 5, 97-112, 2004.

Heuvelink, G., Burrough, P., and Stein, A.: Propagation of errors in spatial modeling with GIS, Int. J. Geogr. Inf. Sci., 3, 303-322, 1989.

Heuvelink, G., Burrough, P., and Stein, A.: Developments in Analysis of Spatial Data Uncertainty Since 1989, in: Classics from IJGIS: twenty years of the International Journal of Geographical Information Science and Systems, edited by: Fisher, P., Taylor and Francis, Boca Raton, FL, 91-95, 2007.

Heuvelink, G. B. M.: Error Propagation in Environmental Modelling with GIS, Taylor \& Francis Ltd, London, England, 127 p., 1998.

Heuvelink, G. B. M.: Analysing Uncertainty Propagation in GIS: Why is it not that simple?, in: Uncertainty in Remote Sensing and GIS, edited by: Foody, G. M. and Atkinson, P. M., John Wiley \& Sons, West Sussex, England, 155-165, 2002.

Hickey, R.: Slope Angle and Slope Length Solutions for GIS, Cartography, 29, 1-8, 2001.

Holmes, K. W., Chadwick, O. A., and Kyriakidis, P. C.: Error in a USGS 30-meter digital elevation model and its impact on terrain modeling, J. Hydrol., 233, 154-173, 2000.

Horn, B.: Hill Shading and the Reflectance Map, Proceedings of the IEEE, 69, 14-47, 1981.

Hunter, G. and Goodchild, M.: Dealing with Error in Spatial Databases: A Simple Case Study, Photogramm. Eng. Rem. S., 61, 529-537, 1995.

Hunter, G. and Goodchild, M.: Modeling the Uncertainty of Slope and Aspect Estimates Derived From Spatial Databases, Geogr. Anal., 29, 35-49, 1997.

Hutchinson, M. F.: A New Procedure for Gridding Elevation and Stream Line Data with Automatic Removal of Spurious Pits, J. Hydrol., 106, 211-232, 1989.

Hutchinson, M. F.: ANUDEM Version 5.2, Centre for Resource and Environmental Studies, The Australian National University, 2006.

Hwang, D., Karmi, H. A., and Byun, D. W.: Uncertainty Analysis of Environmental Models Within GIS Environments, Comput. Geosci., 24, 119-130, 1998.

Jankowski, P., Andrienko, N., and Andrienko, G.: Map-centered exploratory approach to multiple criteria spatial decision making, Int. J. Geogr. Inf. Sci, 15, 101-127, 2001.

Jenson, S.: Applications of Hydrologic Information Automatically Extracted from Digital Elevation Models, Hydrol. Processes, 5, 31-44, 1991.

Jenson, S. and Domingue, J. O.: Extracting topographic structure from Digital Elevation Data for Geographic Information System Analysis, Photogramm. Eng. Rem. S., 54, 1593-1600, 1988.

Johnson, D. L. and Miller, A. C.: A Spatially Distributed Hydrologic Model Utilizing Raster Data Structures, Comput. Geosci., 23, 267-272, 1997.

Journel, A.: Modelling uncertainty and spatial dependence: stochastic imaging, Int. J. Geogr. Inf. Syst., 10, 517-22, 1996.

Karssenberg, D. and Jong, K. D.: Dynamic environmental modelling in GIS: 2. Modelling error propagation, Int. J. Geogr. Inf. Sci, 19, 623-637, 2005.

Kenward, T., Lettenmaier, D. P., Wood, E. F., and Fielding, E.: Effects of Digital Elevation Model Accuracy on Hydrologic Predictions, Remote Sens. Env., 74, 432-444, 2000.

Kienzle, S.: The effect of DEM Resolution on First Order, Second Order and Compound Terrain Derivatives, Transactions in GIS, 8, 83-111, 2004. 
Kuo, W., Steenhuis, T., McCulloch, C., Mohler, C., Weinstein, D., DeGloria, S., and Swaney, D.: Effect of grid size on runoff and soil moisture for a variable-source-area hydrology model, Water Resour. Res., 35, 3419-3428, 1999.

Kyriakidis, P. C., Shortridge, A. M., and Goodchild, M. F.: Geostatistics for conflation and accuracy assessment of digital elevation models. Int. J. Geogr. Inf. Sci, 13, 677-707, 1999.

Lacroix, M. P., Martz, L. W., Kite, G. W., and Garbrecht, J.: Using digital terrain analysis modeling techniques for the parameterization of a hydrologic model, Environ. Modell. Software, 17, 127-136, 2002.

Lagacherie, P., Moussa, R., Cormary, D., and Molenat, J.: Effects of DEM data source and sampling pattern on topographical parameters and on a topography-based hydrological model Application of geographic information systems in hydrology and water resources management, Vienna, Austria, 1996.

Lee, J., Snyder, P., and Fisher, P.: Modeling the Effect of Data Errors on Feature Extraction From Digital Elevation Models, Photogramm. Eng. Rem. S., 58, 1461-1467, 1992.

Li, Z.: Effects of Check Points on the Reliability of DTM Accuracy Estimates Obtained From Experimental Tests, Photogramm. Eng. Rem. S., 57, 1333-1340, 1991.

Li, Z.: Variation of the Accuracy of Digital Terrain Models With Sampling Interval, Photogramm. Rec., 14, 113-128, 1992.

Li, Z.: A comparative study of the accuracy of digital terrain models (DTMs) based on various data models, ISPRS Journal of Photogrammetry and Remote Sensing, 49, 2-11, 1994.

Lindsay, J. B.: Sensitivity of channel mapping techniques to uncertainty in digital elevation data, Int. J. Geogr. Inf. Sci, 20, 669692, 2006.

Lindsay, J. B. and Creed, I. F.: Removal of artifact depressions from digital elevation models: towards a minimum impact approach, Hydrol. Processes, 19, 3113-3126, 2005a.

Lindsay, J. B. and Creed, I. F.: Sensitivity of Digital Landscapes to Artifact Depressions in Remotely-sensed DEMs, Photogramm. Eng. Rem. S., 71, 1029-1036, 2005 b.

Lindsay, J. B. and Creed, I. F.: Distinguishing actual and artefact depressions in digital elevation data, Comput. Geosci., 32, 11921204, 2006.

Liu, R. and Herrington, L.: The Effects of Spatial Data Error on Forest Management Decisions. Proceedings of the GIS 1993 Symposium, Vancouver, British Columbia, 1-8, 1993.

Lopez, C.: An experiment on the elevation accuracy improvement of photogrammetrically derived DEM, Int. J. Geogr. Inf. Sci, 16, 361-375, 2002.

Mark, D.: Network Models In Geomorphology, Modeling in Geomorphological Systems, John Wiley and Sons, New York, 1988.

Martz, L. W. and Garbrecht, J.: An outlet breaching algorithm for the treatment of closed depressions in a raster DEM, Comput. Geosci., 25, 835-844, 1999.

Maune, D. F.: Digital Elevation Model Technologies and Applications: The DEM Users Manual, The American Society for Photogrammetry and Remote Sensing, Bethesda, Maryland, 2001.

Miliaresis, G. C. and Paraschou, C. V. E.: Vertical accuracy of the SRTM DTED level 1 of Crete, Int. J. Appl. Earth Obs. Geoinfo., 7, 49-59, 2005.

Monckton, C.: An Investigation into the spatial structure of error in digital elevation data, Chapter 14, in: Innovations in GIS, edited by: Worboys, M., Taylor and Francis, Bristol, PA, 201-
210, 1994.

Murillo, M. L. and Hunter, G. J.: Assessing uncertainty due to elevation error in a landslide susceptibility model Transactions in GIS, 2, 289-298, 1997.

O'Callaghan, J. F. and Mark, D. M.: The extraction of drainage networks from digital elevation data. Computer Visualization Graph, Image Proceedings of GIS/LIS, 28, 323-344, 1984.

Oksanen, J.: Digital Elevation Model Error In Terrain Analysis, University of Helsinki, Helsinki, Finland, Ph.D., 51 p., 2006.

Oksanen, J. and Sarjakoski, T.: Error Propagation analysis of DEMbased drainage basin delineation, Int. J. Rem. Sens., 26, 30853102, 2005a.

Oksanen, J. and Sarjakoski, T.: Error propagation of DEM-based surface derivatives, Comput. Geosci., 31, 1015-1027, $2005 \mathrm{~b}$.

Oksanen, J. and Sarjakoski, T.: Uncovering the statistical and spatial characteristics of fine toposcale DEM error, Int. J. Geogr. Inf. Sci, 20, 345-369, 2006.

Openshaw, S., Charlton, M., and Carver, S.: Error Propagation: A Monte Carlo Simulation, in: Handling Geographical Information - Methodology and Potential Applications, edited by: Masser, I. and Blakemore, M., John Wiley and Sons, 1991.

Perlitsh, S.: Integration of GIS with the Agricultural Non-Point Source Pollution Model: The Effect of Resolution and Soils Data Sources On Model Input and Output, EPA, 164-174, 1994.

Pike, R.: A Bibliography of Terrain Modeling (Geomorphometry), the Quantitative Representation of Topography-Supplement 4.0, USGS, 158 pp., 2002.

Quattrochi, D. and Goodchild, M.: Scale in Remote Sensing and GIS, CRC Press, Boca Raton, FL, 406 p., 1997.

Quinn, P., Beven, K., Chevallier, P., and Planchon, O.: The Prediction of Hillslope Flow Paths For Distributed Hydrological Modelling Using Digital Terrain Models, Hydrol. Processes, 5, 5979, 1991.

Quinn, P., Beven, K., and Lamb, R.: The $\ln (\mathrm{a} / \mathrm{TanB})$ index: how to calculate it and how to use it within the TOPMODEL framework, Hydrol. Processes, 9, 161-182, 1995.

Refsgaard, J. C., Sluijs, J. P. v. d., Højberg, A. L., and Vanrolleghem, P.: Harmoni-CA Guidance Uncertainty Analysis Guidance 1, A research project supported by the European Commission under the Fifth Framework Programme and contributing to the implementation of the Key Action "Sustainable Management and Quality of Water" within the Energy, Environment and Sustainable Development, Contract no: EVK1-2001-00192, 46, 2004.

Reitsma, F. and Albrecht, J.: Implementing a new data model for simulating processes, Int. J. Geogr. Inf. Sci, 19, 1073-1090, 2005.

Rieger, W.: A phenomenon-based approach to upslope contributing area and depressions in DEMs, Hydrol. Processes, 12, 857-872, 1998.

Rodhe, A. and Seibert, J.: Wetland occurrence in relation to topography: a test of topographic indices as moisture indicators, Agric. For. Meteorol., 98-99, 325-340, 1999.

Saghafian, B., Lieshout, A. M. v., and Rajaei, H.: Distributed Catchment Simulation using a raster GIS, JAG, 2, 199-203, 2000.

Saulnier, G.-M., Obled, C., and Beven, K.: Analytical Compensation between DTM Grid Resolution and Effective Values of Saturated Hydraulic Conductivity Within the TopModel Framework, Hydrol. Processes, 11, 1331-1346, 1997. 
Schoorl, J. M., Sonneveld, M. P. W., and Veldkamp, A.: ThreeDimensional landscape process modelling: The Effect of DEM Resolution, Earth Surf. Proc. Land., 25, 1025-1034, 2000.

Shan, J., Zaheer, M., and Hussain, E.: Study on Accuracy of 1Degree DEM Versus Topographic Complexity Using GIS Zonal Analysis, J. Surv. Eng. ASCE, 129, 85-89, 2003.

Skidmore, A.: A Comparison of techniques for Calculating Gradient and Aspect From A Gridded Digital Elevation Model, Int. J. Geogr. Inf. Sci, 3, 323-334, 1989.

Spear, M., Hall J., and Wadsworth, R.: Communication of Uncertainty in Spatial Data to Policy makers. Spatial Accuracy Assessment in Natural Resources and Environmental Sciences: Second International Symposium, Rocky Mountain Forest and Range Experiment Station, Fort Collins, CO, Report RM-GTR277, 199-207, 1996.

Srivasta, R.: An Overview of Stochastic Spatial Simulation, Spatial Accuracy Assessment in Natural Resources and Environmental Sciences: Second International Symposium, Rocky Mountain Forest and Range Experiement Station, Fort Collins, CO, 13-29, 1996.

Suna, G., Ransonb, K. J., Kharukc, V. I., and Kovacsd, K.: Validation of surface height from shuttle radar topography mission using shuttle laser altimeter, Remote Sens. Env., 88, 401-411, 2003.

Tang, G.-A., Hui, Y.-H., Strobl, J., and Lui, W.-Q.: The impact of resolution accuracy of hydrologic data derived from DEMs, J. Geogr. Sci., 11, 393-401, 2001.

Tarboton, D.: A new method for the determination of flow directions and upslope areas in grid digital elevation models, Water Resour. Res., 33, 309-319, 1997.

Tarboton, D., Bras, R., and Rodriguez-Iturbe, I.: On the extraction of channel networks from digital elevation data, in: Terrain Analysis and Distributed Modeling In Hydrology, edited by: Beven, K. and Moore, I. D., John Wiley and Sons, New York, 85-104, 1993.

Taylor, J.: An Introduction to Error Analysis: The Study of Uncertainties In Physical Measurements, University Science Books, Sausalito, CA, 327 p., 1997.

Theobald, D.: Accuracy and Bias Issues in surface representation, Chapter 9, in: The Accuracy of Spatial Databases, edited by: Goodchild, M. F. and Gopal, S., Taylor and Francis, Bristol, PA, 99-106, 1989.

Thompson, J. A., Bell, J. C., and Butler, C. A.: Digital elevation model resolution: effects on terrain attribute calculation and quantitative soil-landscape modeling, Geoderma, 100, 6789, 2001.

Tobler, W. R.: A computer movie simulating urban growth in the Detroit region, Econ. Geogr., 46, 234-240, 1970.

Toutin, T.: Impact of terrain slope and aspect on radargrammetric DEM accuracy, ISPRS Journal of Photogrammetry and Remote Sensing, 57, 228-240, 2002.

USGS, U.S. Geological Survey: Standards For Digital Elevation Models, Part 1: General, Part 2: Specifications, Part 3: Quality Control., 1997.

Usul, N. and Pasaogullari, O.: Effect of Map Scale and Grid Size for Hydrologic Modelling. GIS and Remote Sensing in Hydrology, Water Resources and Environment, Three Gorges Dam, China, 289, 91-100, 2004.

Valeo, C. and Moin, S.: Grid-resolution effects on a model for inte- grating urban and rural areas, Hydrol. Processes, 14, 2505-2525, 2000.

Van Niel, K., Laffan, S., and Lees, B.: Effect of error in the DEM on environmental variables for predictive vegetation modeling, J. Veg. Sci., 15, 747-756, 2004.

Veregin, H.: Integration of Simulation Modeling and Error Propagation for the Buffer Operation in GIS, Photogramm. Eng. Rem. S., 60, 427-435, 1994.

Veregin, H.: The effects of vertical error in Digital Elevation Models on the determination of flowpath direction, Cartography and GIS, 24, 67-79, 1997.

Vieux, B. and Needham, H.: Nonpoint Pollution Model Sensitivity To Grid Cell Size, J. Water Res. Pl. ASCE, 119, 141-157, 1993.

Vogt, J. V., Colombo, R., and Bertolo, F.: Deriving drainage networks and catchment boundaries: a new methodology combining digital elevation data and environmental characteristics, Geomorphology, 53, 281-298, 2003.

Wang, L.-W. and Trinder, J.: Analysis and evaluation of the DEM derived from TOPSAR Airborne Interferometric SAR System, The Australian Surveyor, 44, 174-182, 1999.

Wang, X. and Yin, Z.-Y.: A comparison of drainage networks derived from digital elevation models at two scales, J. Hydrol., 210, 221-241, 1998.

Wechsler, S. P.: Effect of DEM Uncertainty on Topographic Parameters, DEM Scale and Terrain Evaluation, State University of New York College of Environmental Science and Forestry, Syracuse, NY, Ph.D. Dissertation, 380 p., 2000.

Wechsler, S. P.: Perceptions of Digital Elevation Model Uncertainty by DEM Users, URISA Journal, 15, 57-64, 2003.

Wechsler, S. P. and Kroll, C.: Quantifying DEM Uncertainty and its Effect on Topographic Parameters, Photogramm. Eng. Rem. S., 72, 1081-1090, 2006.

Widayati, A., Lusiana, B., Suyamto, D., and Verbist, B.: Uncertainty and effects of resolution of digital elevation model and its derived features: case study of Sumberjaya, Sumatera, Indonesia, Int. Arch. of Photogrammetry and Remote Sensing, 35, 1013-1018, 2004.

Wilson, J. P. and Gallant, J. C.: Terrain Analysis Principles and Applications, John Wiley \& Sons, New York, NY, 479 p., 2000.

Wise, S.: The Effect of GIS Interpolation Errors on the Use of Digital Elevation Models in Geomorphology, in: Landform Monitoring, Modelling and Analysis, edited by: Lane, S. N., Richards, K. S., and Chandler, J. H., John Wiley and Sons, 300 p., 1998.

Wise, S.: Assessing the quality for hydrological applications of digital elevation models derived from contours, Hydrol. Processes, 14, 1909-1929, 2000.

Wise, S., Haining, R., and Ma, J.: Providing spatial statistical data analysis functionality for the GIS user: the SAGE project, Int. J. Geogr. Inf. Sci, 15, 239-254, 2001.

Wolock, D. and McCabe, G.: Comparison of single and multiple flow direction algorithms for computing topographic parameters, Water Resour. Res., 31, 1315-1324, 1995.

Wolock, D. and Price, C.: Effects of digital elevation model map scale and data resolution on a topography-based watershed model, Water Resour. Res., 30, 3041-3052, 1994.

Wood, J.: The Geomorphological Characterization of Digital Elevation Models, University of Leicester, Leicester, UK, 1996.

Wood, J. D. and Fisher, P. F.: Assessing Interpolation Accuracy in Elevation Models, IEEE Comput Graph, 13, 48-56, 1993. 
Worboys, M. F.: Nearness relations in environmental space, Int. J. Geogr. Inf. Sci, 15, 633-651, 2001.

Yilmaz, M., Usul, N., and Akyurek, Z.: Modeling the Propagation of DEM Uncertainty in Flood Inundation, ESRI User Conference 2004, San Diego, CA, 2004.

Yin, Z.-Y. and Wang, X.: Technical Communication: A CrossScale Comparison of Drainage Basin Characteristics Derived from Digital Elevation Models Earth Planet Sc. Lett., 24, 557567, 1999.

Zerger, A.: Examining GIS decision utility for natural hazard risk modelling, Environmental Modeling \& Software, 17, 287-294, 2002.

Zevenbergen, L. and Thorne, C.: Quantitative Analysis of Land Surface Topography, Earth Surf. Proc. Land., 12, 47-56, 1987.
Zhang, J. and Stuart, N.: Fuzzy methods for categorical mapping with image-based land cover data, Int. J. Geogr. Inf. Sci, 15, 175195, 2001.

Zhang, W. and Montgomery, D.: Digital elevation model grid size, landscape representation and hydrologic simulations, Water Resour. Res., 30, 1019-1028, 1994.

Zhou, Q. and Liu, X.: Error assessment of grid-based flow routing algorithms used in hydrological models, Int. J. Geogr. Inf. Sci, 16, 819-842, 2002.

Zhou, Q. and Liu, X.: Analysis of errors of derived slope and aspect related to DEM data properties, Comput. Geosci., 30, 369-378, 2004. 